\title{
Structure of Rapidly Solidified Al-Fe-Cr-Ce Alloy
}

\author{
Alena Michalcová ${ }^{1,2, a}$, Dalibor Vojtěch ${ }^{1, b}$, Pavel Novák ${ }^{1, c}$, Ivan Procházka ${ }^{3, d}$, \\ Jakub Č́žek ${ }^{3, e}$, Jan Drahokoupil ${ }^{4, f}$, Kateřina Wienerová ${ }^{1}$, Karel Saks| ${ }^{5, g}$, \\ Pawel Rokicki ${ }^{5}$, Zdeněk Spotz ${ }^{5}$ \\ ${ }^{1}$ Institute of Chemical Technology, Prague, Department of Metals and Corrosion Engineering, \\ Technicka 5, 16628 Prague, Czech Republic \\ ${ }^{2}$ Institute of Chemical Technology, Prague, Department of Chemical Technology of Monuments \\ Conservation, Technicka 5, 16628 Prague, Czech Republic \\ ${ }^{3}$ Department of Low-Temperature Physics, Faculty of Mathematics and Physics, Charles \\ University, V Holešovičkách 2, CZ-180 00 Prague 8, Czech Republic \\ ${ }^{4}$ Institute of Physics - Academy of Sciences CR, Na Slovance 2, 18221 Prague 8, Czech \\ Republic \\ ${ }^{5}$ Institute of Materials Research, Slovak Academy of Sciences, Watsonova 47, 04353 Kosice, \\ Slovak Republic

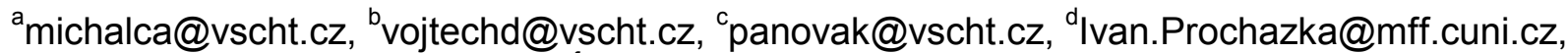 \\ jakub.cizek@mff.cuni.cz, JJanDrahokoupil@seznam.cz, ${ }^{9}$ ksaksl@imr.saske.sk
}

Keywords: Aluminium, Rapid Solidification, Positron Annihilation Spectroscopy

\begin{abstract}
An alloy containing $\mathrm{Al}-3 \mathrm{wt} . \% \mathrm{Cr}-3 \mathrm{wt} . \% \mathrm{Fe}-0.8 \mathrm{wt} . \% \mathrm{Ce}$, was prepared by melt spinning. Structure of obtained ribbons was observed by light, scanning and transmission electron microscopy. It was found out that the structure is very fine. Microhardness of cross sectioned ribbons was also measured. Defects in structure were determined by positron annihilation spectroscopy. The thermal stability of the alloy was observed by comparing rapidly solidified ribbons and ribbons annealed at $400^{\circ} \mathrm{C}$ and at $500^{\circ} \mathrm{C}$ for $100 \mathrm{~h}$.
\end{abstract}

\section{Introduction}

Rapidly solidified (RS) aluminium alloys are promising materials for structural applications. Their main advantage is their superior strength-to-weight ratio. The best mechanical properties and thermal stability are achieved in aluminium - transition metal (TM) - rare earth metal (RE) alloy system with aluminium contents higher than $80 \%[1,2]$. Structure and phase composition of these alloys is strongly dependent on chemical composition and also on cooling rate during rapid solidification.

A systematic study of rapidly solidified alloys started in early 60's of the last century and the first experiments are connected with a name of P. E. Duwez. Since that time, a great variety of methods for preparing rapidly quenched alloys have been developed. Of course, some of them were more successful than the others for example because of simpler construction. At the present time, the most popular methods are: atomisation by inert gas, melt spinning, thin surface layer melting [3] and centrifugal atomization.

The rapid solidification processing involves exceptionally high rates of cooling $\left(10^{4}-10^{8} \mathrm{~K} / \mathrm{s}\right)$ during solidification from the molten state. The levels of undercooling achievable at such high cooling rates lead to significant and often potentially beneficial modifications of rapidly solidified microstructures compared with those produced under conventional conditions [4]. The rapid solidification causes an increase of the solubility of alloying elements, a refinement of the 
microstructure and improves material homogeneity. The rapidly solidified materials also contain many structure defects such as dislocations, vacancies and vacancy clusters. In materials prepared under conventional conditions, these defects are usually accompanied by atmospheres of alloying elements, which enables to decrease internal stress caused by the presence of defects. The cooling rates by rapid solidification process are sufficiently high to suppress diffusion, which is a driving force for formation of large intermetallic phases and content of alloying elements in the matrix is higher than the equilibrium one. It can be expected that rapidly solidified alloy will not contain the atmospheres of alloying elements surrounding the structural defects. At elevated temperatures, diffusions rates of alloying elements increase, so it is possible that the atmospheres around defect can be formed. To prove this, the positron annihilation spectroscopy was used for rapidly solidified ribbons and ribbons annealed at $400^{\circ} \mathrm{C}$ for $100 \mathrm{~h}$.

\section{Experimental}

An alloy containing 93.08 wt.\% $\mathrm{Al}-3.17$ wt.\% $\mathrm{Cr}-2.92$ wt.\% $\mathrm{Fe}-0.83$ wt. \% Ce, denoted as $\mathrm{AlCr} 3 \mathrm{Fe} 3 \mathrm{Ce} 1$, was prepared by melt spinning with circumferential speed of cooling wheel of 20 $\mathrm{m} / \mathrm{s}$. Chemical composition was determined by x-ray fluorescence spectroscopy (XRF) using spectrometer ARL 9400 XP. The ribbons were observed at cross section by Olympus PME3 light microscope. Vickers hardness HV 0.02 was also determined on the cross sectioned ribbons. Transmission electron microscopy (TEM) samples were prepared by grinding the $3 \mathrm{~mm}$ disc to the thickness of $50 \mu \mathrm{m}$. Consequently, they were dimpled by Gatan Dimple Grinder, Model 656 to the final dimple thickness of $10 \mu \mathrm{m}$ and precision ion polished by Gatan PIPS, the Model 691. TEM samples were examined by using a transmission electron microscope Jeol 3010 (accelerating voltage $300 \mathrm{kV}$ ). The conventional $\mathrm{x}$-ray diffraction was measured on the wheel side of the ribbon by PAN analytical X'Pert PRO + High Score Plus with $\mathrm{Cu}$ anode. The Topas3 program was utilized for Rietveld structure refinement. High energy x-ray diffraction measurements were performed at BW5 beamline located at the DORIS III positron storage ring in DESY Hamburg. Monochromatic synchrotron radiation with wavelength of $\lambda=0.124 \AA$ was used for measurement. Positron annihilation spectroscopy (PAS) involves several experimental techniques: (i) positron lifetime (LT) spectroscopy makes it possible to identify the type of defects and to determine their concentrations; (ii) coincidence measurements of Doppler broadening (CDB) is a unique method which brings information about the local chemical environment of defects. The detailed description is given elsewhere $[5,6]$. The time resolution of the digital LT spectrometer was $150 \mathrm{ps}\left(\mathrm{FWHM},{ }^{22} \mathrm{Na}\right)$. At least $10^{7}$ annihilation events were accumulated in each LT spectrum. At least $10^{8}$ events were collected in each CDB spectrum. The relative changes of Doppler profiles were followed as ratio curves of the Doppler profile normalized counts to those of the well annealed pure Al (99.9999\%) reference profile.

\section{Results and Discussion}

Structure of rapidly solidified $\mathrm{AlCr} 3 \mathrm{Fe} 3 \mathrm{Ce} 1$ alloy was very fine, as illustrated on the cross sectioned in Fig. 1. The value of ribbons thickness was about $50 \mu \mathrm{m}$ and the ribbon exhibited structural gradient caused by decreasing cooling rates with increasing distance from cooling wheel. The wheel side of the ribbon is placed in the down part of Fig. 1. The alloy was formed by fcc-Al grains and intermetallic phases surrounding the grains, as shown in Fig. 2. 


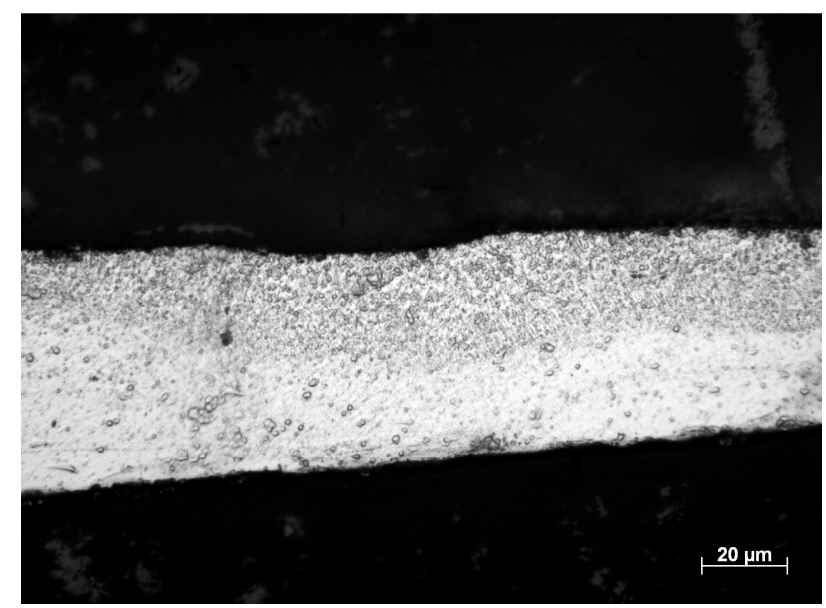

Fig. 1. Cross section of RS AlCr3Fe3Ce1 alloy ribbon (LM)

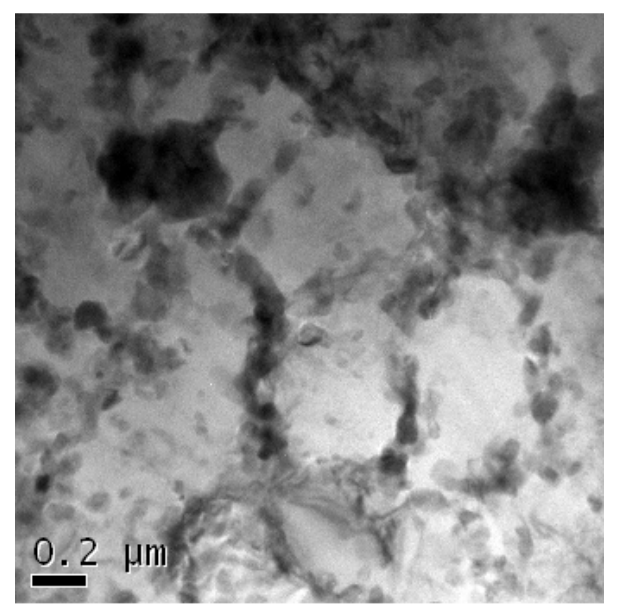

Fig. 2. TEM micrograph of RS AICr3Fe3Ce1 alloy

The structure was not changed after annealing at $400^{\circ} \mathrm{C}$ for $100 \mathrm{~h}$, as documented in Fig. 3 . On the other hand, an annealing at $500^{\circ} \mathrm{C}$ for $100 \mathrm{~h}$ lead to significant microstructural changes, such as grain coarsening and occurrence of new phase, as shown in Fig. 5. The comparison of grain sizes of $\mathrm{RS}$ and annealed materials is given in Tab. 1.

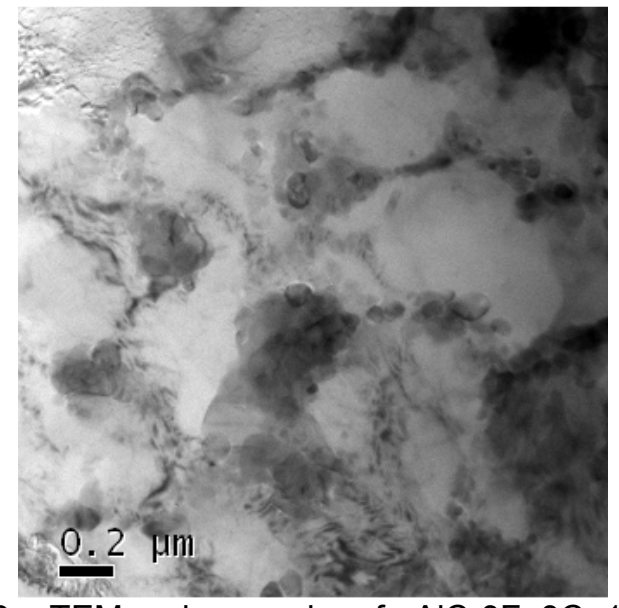

Fig. 3. TEM micrograph of $\mathrm{AlCr} 3 \mathrm{Fe} 3 \mathrm{Ce} 1$ alloy annealed at $400^{\circ} \mathrm{C}$ for $100 \mathrm{~h}$

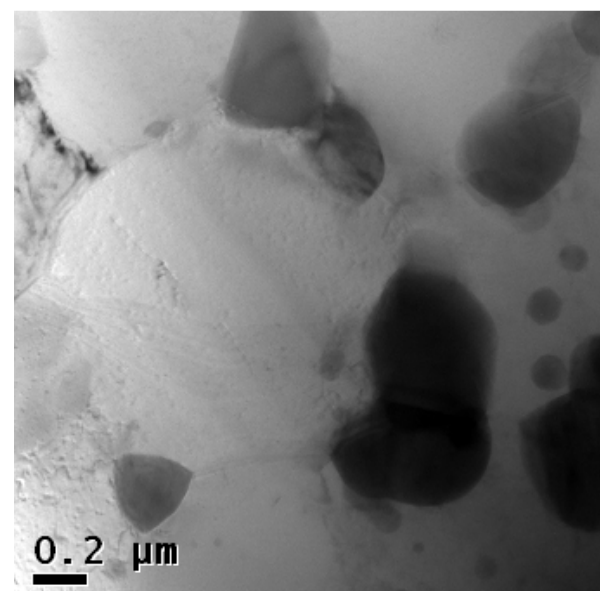

Fig. 4. TEM micrograph of AlCr3Fe3Ce1 alloy annealed at $500^{\circ} \mathrm{C}$ for $100 \mathrm{~h}$

Decrease of hardness value was also observed after long term annealing at $500^{\circ} \mathrm{C}$, as can be seen in Tab. 1. While the hardness of RS alloy and alloy annealed at $400^{\circ} \mathrm{C}$ are approximately the same, the value for alloy annealed at $500^{\circ} \mathrm{C}$ is significantly lower. Grain size was determined by two ways by image analysis and by Rietveld refinement of XRD patterns, which allows determining the size of coherently diffracting domains. This is the reason for difference in absolute values obtained by different methods. However, the trend in grain size evolution was observed by both methods. The grain size for RS alloy and annealed at $400^{\circ} \mathrm{C}$ was the same within the measurement accuracy, the grain size of alloy annealed at $500^{\circ} \mathrm{C}$ was approximately two-times higher.

\begin{tabular}{|l|l|l|l|}
\hline \multicolumn{4}{|l|}{$\begin{array}{l}\text { Tab.1. Hardness, average grain size determined by image analysis and by Rietveld refinement from XRD } \\
\text { patterns for RS AICr3Fe3Ce1 alloy and alloys annealed at } 400^{\circ} \mathrm{C} \text { and } 500^{\circ} \mathrm{C} \text { for } 100 \mathrm{~h}\end{array}$} \\
\hline Alloy & Hardness HV0.02 & $\begin{array}{l}\text { Grain size by image } \\
\text { analysis } / \mathrm{nm}\end{array}$ & Grain size by XRD / nm \\
\hline RS & $116 \pm 4$ & $294 \pm 6$ & $165 \pm 4$ \\
\hline annealed $400^{\circ} \mathrm{C} / 100 \mathrm{~h}$ & $110 \pm 3$ & $313 \pm 6$ & $148 \pm 3$ \\
\hline annealed $500^{\circ} \mathrm{C} / 100 \mathrm{~h}$ & $71 \pm 1$ & $509 \pm 19$ & $211 \pm 5$ \\
\hline
\end{tabular}




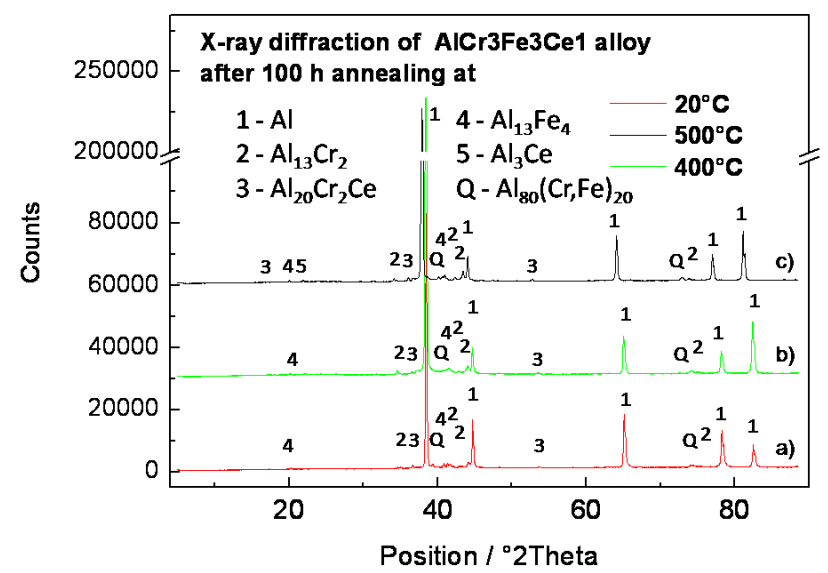

Fig. 5. XRD patterns of AICr3Fe3Ce1 alloy a) RS, b) annealed $400^{\circ} \mathrm{C} / 100 \mathrm{~h}, \mathrm{c}$ ) annealed $500^{\circ} \mathrm{C} / 100 \mathrm{~h}$

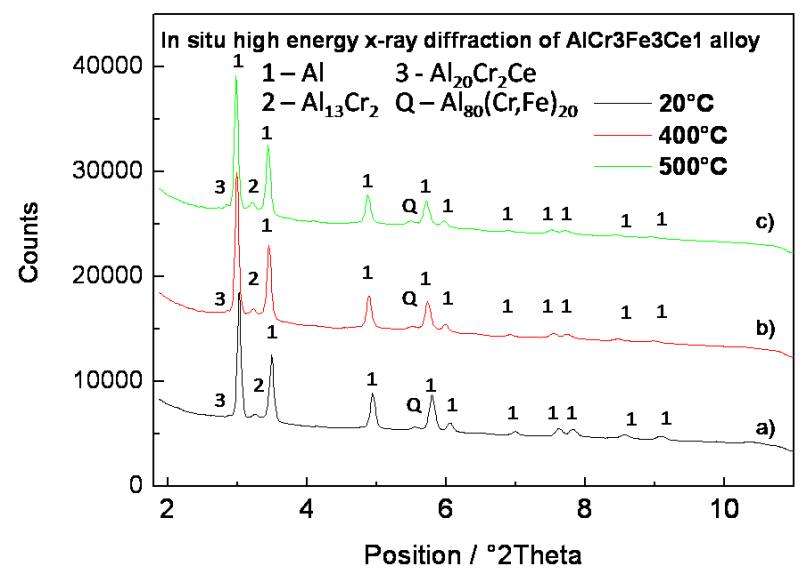

Fig. 6. High energy XRD patterns of $\mathrm{AICr} 3 \mathrm{Fe} 3 \mathrm{Ce} 1$ alloy a) at $20^{\circ} \mathrm{C}$, b) at $400^{\circ} \mathrm{C}, \mathrm{C}$ ) at $500^{\circ} \mathrm{C}$

The RS alloy composed of fcc $-\mathrm{Al}, \mathrm{Al}_{13} \mathrm{Cr}_{2}$ and $\mathrm{Al}_{20} \mathrm{CeCr}_{2}$ intermetallic phases and small amount of $\mathrm{Al}_{80}(\mathrm{Cr}, \mathrm{Fe})_{20}$ quasicrystalline phase. After annealing at $500^{\circ} \mathrm{C}$ for $100 \mathrm{~h}$ an $\mathrm{Al}_{3} \mathrm{Ce}$ phase arisen. This phase was not observed during in-situ high energy diffraction at $500^{\circ} \mathrm{C}$, see Fig. 6 . The process of new phase formation is strongly dependent on diffusion rate of alloying elements and so the new phase can be detected after long term annealing and not directly after heating of the alloy.

The main structure defects detected in RS AlCr3Fe3Ce1 alloy by PAS were dislocations. They were not distributed homogenously in material, as was proven by LT, and they formed dislocation walls with dislocation density of $4 \times 10^{14} \mathrm{~m}^{-2}$, while the average dislocation density was $9 \times 10^{13} \mathrm{~m}^{-2}$. For the PAS experiments, pseudo- bulk sample was prepared formed by several ribbons. In this case, the dislocation walls corresponded to the wheel sides of ribbons, that were cooled at highest quenching rates and so they contain more structure deformation. The chemical composition in vicinity of dislocations was the same as matrix composition, as proven by CDB. Results obtained for ribbons annealed at $400^{\circ} \mathrm{C}$ for $100 \mathrm{~h}$ were similar to results of RS ribbons. In further research, the ribbons annealed at $500^{\circ} \mathrm{C}$ for $100 \mathrm{~h}$ will by studied by PAS.

\section{Conclusion}

The rapidly solidified ribbons of $\mathrm{AlCr} 3 \mathrm{Fe} 3 \mathrm{Ce} 1$ alloy were formed by fine- grained fcc- $\mathrm{Al}$, intermetallic phases and small amount of quasicrystalline phase. The alloy exhibit excellent thermal stability at $400^{\circ} \mathrm{C}$. Grain coarsening and formation of new phase was observed at $500^{\circ} \mathrm{C}$.

\section{Acknowledgement}

This work was financially supported by research projects MSM 6046137302, KAN 300100801 and "MAMINA" (Grant Agreement PITN-GA-2008-211536).

\section{References}

[1] A. Inoue, et al.,: NanoStructured Materials, 11 (1999)221

[2] K. Saksl, et al., Journal of Applied Physics 97, 113507 (2005)

[3] B. Bártová, et al.,: Journal of Alloys and Compounds, 387 (2005), 193-200

[4] Z. Zhang, et al.,:, Journal of Crystal Growth 281 (2005) 646-653

[5] F. Bečvář, et al.,: Nucl. Instr. Meth. A 539 (2005) 372

[6] F. Bečvář, et al.,: Acta Physica Polonica A 113 (2008) 1279 
Materials Structure \& Micromechanics of Fracture VI

10.4028/www.scientific.net/KEM.465

Structure of Rapidly Solidified AI-Fe-Cr-Ce Alloy

10.4028/www.scientific.net/KEM.465.199

\section{DOI References}

[1] A. Inoue, et al.,: NanoStructured Materials, 11 (1999)221 doi:10.1016/S0965-9773(99)00035-5

[2] K. Saksl, et al., Journal of Applied Physics 97, 113507 (2005) doi:10.1063/1.1914955

[4] Z. Zhang, et al.,.:, Journal of Crystal Growth 281 (2005) 646-653 doi:10.1016/j.jcrysgro.2005.04.052 